\title{
Marginal Bone Loss around Morse Taper Connection Implants in Osseointegration Period
}

\section{Adriane Yaeko Togashi ${ }^{1}$, Silmara Assunta Castaman², Adriano Yaeko Piccolotto ${ }^{2}$ and Eleonor Alvaro Garbin²}

${ }^{1}$ Department of Periodontology and Dental Implantology, School of Dentistry of Cascavel, UNIOESTE, Brazil

${ }^{2}$ State University of Western Parana, UNIOESTE Cascavel, Parana, Brazil

Corresponding author: Adriane Yaeko Togashi, Department of Periodontology and Dental Implantology, School of Dentistry of Cascavel, UNIOESTE, Brazil, Tel: +55 45 3220-3159; E-mail: Adriane.Togashi@unioeste.br

Rec Date: May 1, 2016; Acc Date: June 13, 2016; Pub Date: June 20, 2016

Copyright: (c) 2016 Togashi AY, et al. This is an open-access article distributed under the terms of the Creative Commons Attribution License, which permits unrestricted use, distribution, and reproduction in any medium, provided the original author and source are credited.

Citation: Togashi AY, Castaman SA, Piccolotto AY, et al. Marginal bone loss around morse taper connection implants in osseointegration period. J Biomedical Sci. 2016, 5:3.

\section{Abstract}

Reason and purpose of the study: Bone loss, particularly at the level of the marginal bone crest, continues to be one of the main complications of implant treatment that compromises osseointegration and the rehabilitation. The aim of the present study was to evaluate radiographic marginal bone loss around short Morse taper connection implants and the survival rate of these implants 7, 30 and 90 days after placement in severely resorbed jaws.

Methods: Twelve patients were divided into two groups: a study group consisting of 20 implants measuring $6 \mathrm{~mm}$ in length and $3.75 \mathrm{~mm}$ in diameter, and a control group consisting of 20 implants measuring $8 \mathrm{~mm}$ in length and $3.75 \mathrm{~mm}$ in diameter. All surgeries were performed according to the protocol of morse taper connection implant of the Kopp System. The results were compared by one-way analysis of variance and the Tukey test.

Results: There was no significant difference between groups at any of the time points studied. The mean bone crest/ implant shoulder distance was $1,36 \mathrm{~mm}(\mathrm{SD}=1.01)$ on the mesial surface and was $1,10 \mathrm{~mm}(\mathrm{SD}=0.87)$ on the distal surface for the $6-\mathrm{mm}$ implants and $1,42 \mathrm{~mm}(S D=0.83)$ on the mesial surface and was $1,15 \mathrm{~mm}(\mathrm{SD}=0.76)$ on the distal surface for the $8-\mathrm{mm}$ implants after 90 days of implant placement. Two of the 40 implants were lost (one per group), corresponding to a survival rate of $95 \%$.

Conclusion: Within the limitations of this study, we conclude that 6-mm long Morse taper connection implants present levels of crestal bone remodeling similar to those of 8-mm long implants.

Keywords: Bone resorption; Dental implants; Morse taper dental implant-abutment connection

\section{Introduction}

Bone loss, particularly at the level of the marginal bone crest, continues to be one of the main complications of implant treatment that compromises osseointegration and the longterm success of rehabilitation [1,2]. There is consensus in the literature that the average bone loss around implants is $1 \mathrm{~mm}$ in the first year of prosthesis installation and then remains constant at $0.1 \mathrm{~mm}$ per year [3]. Bone loss around the implant may also occur early due to etiological factors such as surgical trauma resulting from overheating, implant position, formation of biological space, surgical technique, and implant design [1,2,4-6].

Osteotomy, a procedure used for the placement of osseointegrated implants, has been indicated as one of the probable causes of early peri-implant bone loss due to the creation of devitalized bone around the implant. This devitalized zone is the result of interruption of blood supply and the heat generated during osteotomy, especially in cortical bone $[2,5,7,8]$. Apical-coronal implant position is another factor that influences peri-implant bone loss $[1,4,9]$. Other etiologies of early periimplant crestal bone loss, such as smoking, immediate versus late implant placement and non-threaded implants, are not conclusive and require further investigation $[6,10]$.

One advantage of Morse taper connection implants of the frictional system is the absence of an implant-abutment interface at the level of the bone crest $[8,11-14]$. Studies have shown less marginal bone loss around this type of dental implant [15]. Another characteristic of these implants is the shorter smooth shoulder $(0.5 \mathrm{~mm})$ when compared to conventional implants (1.8 to $2.8 \mathrm{~mm}$ ). The purpose of this reduction is to increase the treated surface area of the implant, with a consequent increase in bone contact area which contributes to osseointegration and reduces the extent of crestal bone resorption $[16,17]$.

Marginal bone loss is an even greater matter of concern when short implants are used. These implants are employed in 
situations of short bone height or anatomical accidents such as maxillary sinus pneumatization and proximity to the mandibular canal $[13,16]$. Various bone grafting techniques have been applied to overcome these physiological and anatomical limitations. Despite high survival rates of these procedures, many patients are unable or unwilling to undergo these surgeries because of the need for multiple complex procedures, poor physical conditions, increased postoperative sensitivity, high cost, and long duration of treatment [16]. Although several studies have reported higher failure rates for short implants [18-20], clinical reports indicate that survival rates are comparable to those of longer implants [8,16,21-23]. Misch et al. [23] reviewed the literature on the failure rates of implant management in partially edentulous patients receiving dental implants shorter than $10 \mathrm{~mm}$ in the posterior region of the dental arch between 1991 and 2003. The implant survival rate was $85.3 \%$ for 2,837 short implants. Furthermore, these authors and others demonstrated that most failures occur after prosthetic load and that the failure rate does not depend on implant length $[19,22,24,25]$. Therefore, placement of short implants might be a suitable alternative for patients with inadequate bone height in the posterior maxilla.

Considering that implant positioning relative to the alveolar crest can contribute to crestal bone resorption around morse taper connection implants. Subcrestal position those implants has been proposed to decrease the risk of exposure of the metal top of the implant and to have sufficient space in a vertical dimension to create emergence profile. Although osseointegrated implants have been extensively studied, there are few reports comparing less than $8-\mathrm{mm}$ long and $8-\mathrm{mm}$ long implants during the initial healing phase. Therefore, the objective of the present clinical research was to evaluate whether radiographic marginal bone loss around 6-mm long morse taper connection implants and the survival rate of these implants during osseointegration are similar to those of $8-\mathrm{mm}$ long implants inserted in a subcrestal position.

\section{Methods}

\section{Patient selection and study design}

A controlled clinical research using titanium implants with morse taper connection was conducted. The patients were recruited from the Undergraduate and Postgraduate clinics of the Department of Implantology, School of Dentistry of Cascavel, Parana, Brazil. The study was approved by the Ethics Committee of the State University of Western Parana (Process No. 488/2009-CEP) and the patients signed a free informed consent form after they had received detailed information about the study.

Twelve patients were selected and divided into two groups: a study group consisting of 20 implants measuring $6 \mathrm{~mm}$ in length and $3.75 \mathrm{~mm}$ in diameter, and a control group consisting of 20 implants measuring $8 \mathrm{~mm}$ in length and $3.75 \mathrm{~mm}$ in diameter. The implants were placed in edentulous maxillary sites that required prosthetic rehabilitation. Patients with insufficient bone volume and those who required dentoalveolar reconstruction (e.g., bone grafts) were excluded. Of the 12 patients, $5(41,7 \%)$ were male and 7 (58,3\%) were female. Patients had between the ages of 39 and 59 years (mean age was 48 years).

Criteria for inclusion in the study were age of 18 years or older; willingness to cooperate with the requirements of the study, no systemic condition such as diabetes mellitus, osteoporosis, cancer, irradiation or blood dyscrasias; good oral hygiene; sufficient alveolar bone volume at the implant recipient site (width $\geq 6 \mathrm{~mm}$ and height $\geq 8 \mathrm{~mm}$ ) exclusively for the study group, and type I-III bone quality. Exclusion criteria were pregnancy or breast-feeding; smoking and use of alcohol or drugs; previous reconstruction at the implant recipient site; insufficient alveolar bone volume at the implant recipient site (width $<6$ and height $<8 \mathrm{~mm}$ ); presence of residual roots at the recipient site; type IV bone quality decreases implant stability; keratinized mucosa $<2 \mathrm{~mm}$ at the implant recipient site; stomatological diseases, and clinical signs of temporomandibular dysfunction and bruxism.

Molds were then prepared from the patients who met the inclusion criteria. These cases were planned. All clinical and radiographic procedures were performed at the Dental Implantology clinics of the State University of Western Parana, Brazil.

\section{Surgical procedures}

Titanium implants of the Kopp System (Kopp Industria e Comércio de Produtos Odontológicos Ltda., Curitiba, Parana, Brazil), measuring $3.75 \mathrm{~mm}$ in diameter and 6 or $8 \mathrm{~mm}$ long, were placed under local anesthesia by two surgeons in a single intervention. The surgical procedure consisted of an incision in the alveolar ridge crest for preservation of the keratinized mucosa. Next, lingual and buccal mucoperiosteal flaps were carefully elevated from the top of the alveolar crest. The implant socket was fabricated with burs according to the protocol of the system and primary stability was always achieved. The implants were placed 1 to $2 \mathrm{~mm}$ below the bone crest. The mucoperiosteal flaps were repositioned for healing by first intention and secured with 5-0 Nylon suture. After one week, the sutures were removed and postoperative control was performed.

\section{Postoperative care}

The patients received an antibiotic (500 $\mathrm{mg}$ amoxicillin at 8-h intervals or $500 \mathrm{mg}$ erythromycin at 6-h intervals for patients who are allergic to penicillin) for 7 days starting $1 \mathrm{~h}$ after surgery; anti-inflammatory drug (100 mg nimesulide at $12-\mathrm{h}$ intervals) for 5 days starting $1 \mathrm{~h}$ before surgery, and analgesic (500 $\mathrm{mg} / \mathrm{ml}$ sodium dipyrone at 6 -h intervals) in the case of pain.

The patients were advised to avoid any trauma to the implant sites and to rinse the mouth with $0.12 \%$ chlorhexidine digluconate for at least 1 minute, twice a day, for one week. The sutures were removed after 7 days and the patient was advised to properly clean the treated area. 
Radiographs were obtained for the two groups after implant placement.

\section{Radiographic evaluation}

Intraoral periapical radiographs were obtained before implant placement and 7, 30 and 90 days after surgery. Periodic visits were held for maintenance and for the reinforcement of oral hygiene instructions at 7,30 and 90 days after implant placement. The paralleling technique was used. Radiographs were taken using digital radiographic sensor (Kavo-Kerr), an individual acrylic positioning device, and an exposure time of 0.4 seconds. For the evaluation of changes in peri-implant crestal bone height, a single examiner measured the linear distance (in $\mathrm{mm}$ ) from the implant shoulder to the most coronary part of the mesial and distal bone crest [7] using the Image Tool image analysis program (University of Texas).

Figure 1 illustrate the periapical radiographs of the $6-\mathrm{mm}$ and $8-\mathrm{mm}$ implants. Crestal bone measurements were made on the periapical radiographs obtained for the $6-\mathrm{mm}$ and $8-\mathrm{mm}$ implants. The length of the implant ( 6 or $8 \mathrm{~mm}$ ) represents the reference to compensate for radiographic distortion. Next, crestal bone measurements were obtained on the mesial and distal side for all implants at the pre-established time points. The apparent dimension of each implant (directly measured on the radiograph) was compared to the true implant length, and the following equation: [Rx implant length/ True implant length $=\mathrm{Rx}$ crestal bone measurements/ True crestal bone measurements] was used to stablish the eventual amount of vertical bone alteration at the mesial and distal site of the implant [26].

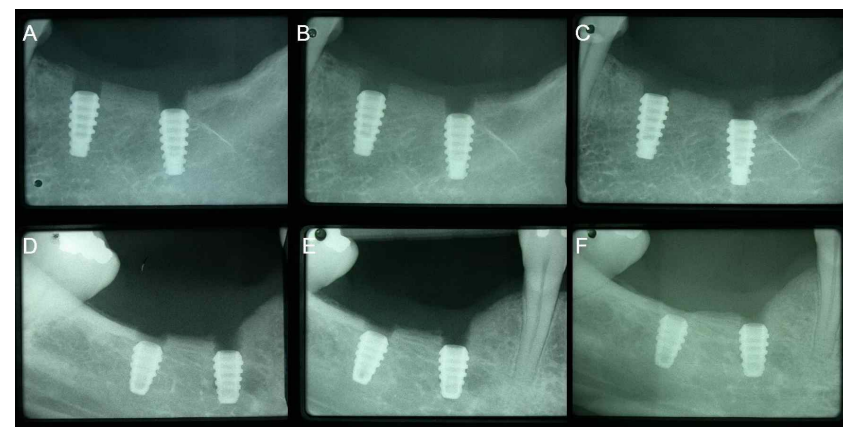

Figure 1 A) Periapical radiographs obtained for the 8-mm implant 7 days after surgery. B) Periapical radiographs obtained for the 8-mm implant 30 days after surgery. C) Periapical radiographs obtained for the $8-\mathrm{mm}$ implant 90 days after surgery. D) Periapical radiographs obtained for the 6$\mathrm{mm}$ implant 7 days after surgery. E) Periapical radiographs obtained for the $6-\mathrm{mm}$ implant 30 days after surgery. F) Periapical radiographs obtained for the $6-\mathrm{mm}$ implant 90 days after surgery.

The results were compared by one-way analysis of variance and the Tukey test. A P value $<0.05$ was considered to indicate statistical significance. Statistical analysis was performed using the Bioestat 4 program.

\section{Results}

Forty implants (20 implants measuring $3.75 \times 6 \mathrm{~mm}$ and 20 implants measuring $3.75 \times 8 \mathrm{~mm}$ ) were placed in the patients according to the number of missing teeth and bone availability. Twelve (30\%) implants were placed in the maxilla and 28 (70\%) in the mandible. Only one implant was placed in the anterior region and the remaining ones in the posterior region of the jaws. As reported by the patients, the first lower molars were the first teeth to be lost. Most implants $(n=8,20 \%)$ were placed at the site of tooth 46 . Six implants were placed at the site of tooth 36 , corresponding to $15 \%$ of the sample.

Fourteen $(35 \%)$ of the $8-\mathrm{mm}$ implants were placed in the mandible and $6(15 \%)$ in the maxilla. The same percentages were observed for the $6-\mathrm{mm}$ implants $(35 \%$ in the mandible and $15 \%$ in the maxilla).

Two of the 40 implants were lost (one per group), corresponding to a survival rate of $95 \%$. In the study group, one posterior mandibular implant was lost after 30 days of use due to exposure and mobility of the implant. In the control group, the implant was lost after 20 days of use due to postoperative sensitivity in the posterior maxillary region. Only one of the 12 patients reported mild postoperative paresthesia in the lower lip. However, the symptoms had improved at the end of the 3month follow-up period. The remaining 38 implants met the criteria of success proposed by Karoussis et al. [10] and Misch et al. [27]. Radiographic examination showed no radiolucency at the bone-implant interface for any of the implants, indicating survival of dental implants during the period studied.

Figure 1 and Table 1 show the mean distance (in $\mathrm{mm}$ ) of the mesial and distal bone crests from the two types of implants $(3.75 \times 6 \mathrm{~mm}$ and $3.75 \times 8 \mathrm{~mm})$ at 7,30 and 90 days after implant placement. There was no significant difference between groups at any of the time points studied. However, comparison of mesial and distal bone crest height of the two implants over time showed a significant difference between mesial crest height of the $8-\mathrm{mm}$ implant at 7 days $(2.15 \mathrm{~mm})$ and distal crest height of the $6-\mathrm{mm}$ implant at 30 days $(1.15 \mathrm{~mm})$ and 90 days $(1.1 \mathrm{~mm})$, and also distal crest height of the $8-\mathrm{mm}$ implant at 90 days $(1.15 \mathrm{~mm}$ ). The $\mathrm{p}$ value was 0.002 (Figure 2 ).

The mean bone crest/shoulder distance of the implant during a period of 7, 30 and 90 days after implant placement in a subcrestal position revealed similar bone remodeling of the implant crests for the $6-\mathrm{mm}$ and $8-\mathrm{mm}$ groups. However, the mean bone crest/implant shoulder distance was $1,36 \mathrm{~mm}$ $(S D=1.01)$ on the mesial surface and was $1,10 \mathrm{~mm}(S D=0.87)$ on the distal surface for the $6-\mathrm{mm}$ implants and $1,42 \mathrm{~mm}(\mathrm{SD}=0.83)$ on the mesial surface and was $1,15 \mathrm{~mm}(S D=0.76)$ on the distal surface for the 8-mm implants after 90 days of follow-up. Difference between 7 and 90 days of the mesial and distal bone crest height values of the $6-\mathrm{mm}$ long implants over time was $0,42 \mathrm{~mm}$ and $0,32 \mathrm{~mm}$, respectively, and for 8-mm long implants over time was $0,73 \mathrm{~mm}$ and $0,53 \mathrm{~mm}$, respectively. 


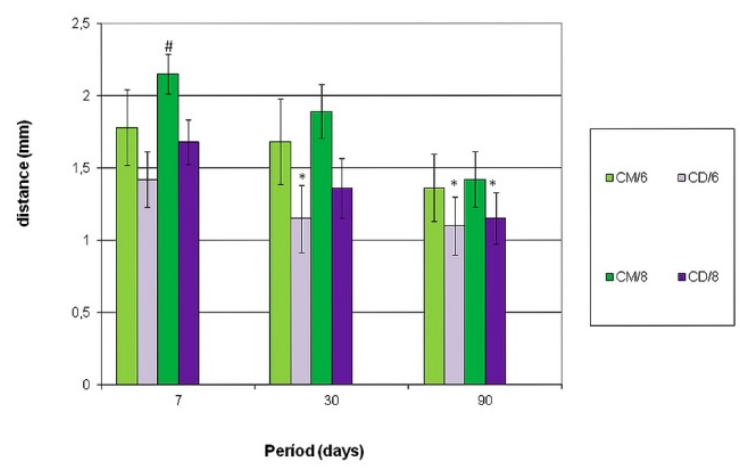

Figure 2 Mean distance (in $\mathrm{mm}$ ) between the implant shoulder and the mesial and distal bone crests of the two types of implants $(3.75 \times 6 \mathrm{~mm}$ and $3.75 \times 8 \mathrm{~mm})$ at 7,30 and 90 days after implant placement. Differents symbols indicate a significant difference. Data are expressed as mean $\pm \mathrm{SD}$; Tukey test, *: $p<0.05$; \#: $p<0.05$, for $C D / 630$ days group; $C D / 6$ and $\mathrm{CD} / 890$ days; NS, non-significant: $p>0.05$.

\section{Discussion}

The 6-mm implants used in the present study were considered to be short when compared to the mean length of $7.9 \mathrm{~mm}$ established in the literature $[13,23]$. In contrast to previous studies, this investigation evaluated peri-implant bone loss around 6-mm long Morse taper connection implants with a 3.75-mm regular platform. Radiographic evaluation revealed similar levels of crestal bone remodeling on the mesial and distal sides for the short $(6 \mathrm{~mm})$ and control $(8 \mathrm{~mm})$ implants (Figure 1 and Table 1). The fact that shorter implants yield similar results as $8-\mathrm{mm}$ implants has also been reported in the literature. In addition, studies have demonstrated the possibility of implant placement in areas with low bone height without the need for advanced surgery or bone grafting $[8,28]$.

Anatomical limitations can interfere with the position of osseointegrated implants. In the posterior maxilla, implant placement is limited by the extension of the maxillary sinus cavity and, in the posterior mandible, by the position of the inferior alveolar nerve. Techniques for vertical and horizontal reconstruction of the posterior ridge such as autogenous bone grafting, guided bone regeneration, inferior alveolar nerve repair and maxillary sinus lift are associated with high morbidity [13]. In the present study, the design and size of the implant used permitted the placement of most implants (70\%) in the mandible beyond the mental foramen into type II or III bone according to the classification of Misch [23]. With respect to bone quality, bone density is not only responsible for mechanical stability of the implant during healing, but also for the distribution and transmission of stresses from the prosthesis to the bone-implant interface after healing [29].

Table 1 Mean distance of the mesial and distal crestal bone measurement from the implant shoulder (implants of $3.75 \times 6$ $\mathrm{mm}$ and $3.75 \times 8 \mathrm{~mm}$ ) at 7, 30 and 90 days after implant placement. Data are expressed as mean \pm SD; Tukey test, NS, non-significant: $p>0.05$

\begin{tabular}{|c|c|c|c|c|}
\hline Days & $\begin{array}{l}\text { CM/6 (mm) } \\
\text { Mean } \pm \text { SD }\end{array}$ & $\begin{array}{l}\text { CD/6 (mm) } \\
\text { Mean } \pm \text { SD }\end{array}$ & $\begin{array}{l}\text { CM/8 (mm) } \\
\text { Mean } \pm \text { SD }\end{array}$ & $\begin{array}{l}\text { CD/8 (mm) } \\
\text { Mean } \pm \text { SD }\end{array}$ \\
\hline 7 & $1,78 \pm 1.13$ & $1,42 \pm 0.83$ & $2,15 \pm 0.60$ & $1,68 \pm 0.67$ \\
\hline 30 & $1,68 \pm 1.29$ & $1,15 \pm 1.01$ & $1,89 \pm 0.80$ & $1,36 \pm 0.89$ \\
\hline 90 & $1,36 \pm 1.01$ & $1,10 \pm 0.87$ & $1,42 \pm 0.83$ & $1,15 \pm 0.76$ \\
\hline
\end{tabular}

The less dense the bone, less bone will be in contact with the implant body $[23,30,31]$. This fact may explain the high survival rate of $95 \%$ obtained in the present study. In addition, the number of implants placed in the mandible was the same for the 6-mm and 8-mm implants, demonstrating the similarity of the two groups.

The stability of the peri-implant bone crest interferes with the esthetic outcome of dental implants, such as size of the prosthetic crown and presence of interdental papilla. One major concern in the case of short implants is the gradual peri-implant bone resorption over time, particularly in the first year, which can reach $1 \mathrm{~mm}[15,32]$. Therefore, some factors that contribute to crestal bone resorption need to be controlled, including position of the implant at the bone crest level, type of connection between the implant and prosthetic component, and surgical procedure used for implant placement. In the present study, all implants with a regular platform and a Morse taper connection were placed 1 to $2 \mathrm{~mm}$ below the bone crest. Radiographic evaluation of marginal bone loss showed a mean reduction in bone height above the implant shoulder ranging from 0.32 to $0.73 \mathrm{~mm}$ over the period studied. Similar results have been reported by Degidi et al. [32] who analyzed histologically implants placed at the level of the bone crest and 1 to $3 \mathrm{~mm}$ below the crest. Peri-implant bone resorption ranged from 0.5 to $1.5 \mathrm{~mm}$ for implants positioned at the level of the bone crest and from 0 to $0.5 \mathrm{~mm}$ for intraosseous implants. A difference exists between implants that are buried under the gum during the healing period and those that are not, since partial exposure contributes to the accumulation of bacterial plaque and can cause inflammation [16,33-35]. Therefore, all implants were buried under the gum tissue during the study period.

Another observation in this present study was the mean mesial and distal crestal bone loss from 0.32 to $0.73 \mathrm{~mm}$ for the 6-mm and the 8- $\mathrm{mm}$ implants over the period studied. It can be suggested that major changes have been observed between the mean distance from the implant shoulder to the crestal bone-toimplant contact at 7- and 90-days examinations. This fact may have relevant implications for long-term implant survival since excellent bone stability occurs mainly after the first year of osseointegration. Mangano et al. [15] found a mean distance of 0.89 and $1.10 \mathrm{~mm}$ between the implant shoulder and the first 
visible bone contact after 1 and 6 years of functional loading, respectively.

Short implants present disadvantages in terms of primary stability and stress distribution. The use of threaded short implants with a wide diameter is therefore recommended in order to obtain better locking, a greater surface area and better distribution of occlusal loads [29]. Other disadvantages of short implants include an unfavorable crown/implant ratio, low bone density in the premolar and molar regions, and a smaller contact surface of the implant for osseointegration $[16,19,28]$. On the other hand, short implants have surgical advantages when compared to long implants, such as minimizing the need for extensive bone grafting; shorter treatment duration; lower treatment cost; less discomfort; lower surgical risk; lower risk of maxillary sinus perforation, paresthesia, overheating during osteotomy and involvement of the root of the adjacent tooth, and ease of use [23].

Advantages of these shorter implants when compared to major bone grafting include their lower cost, shorter treatment duration, lower morbidity and fewer postoperative complications, as well as better acceptance by the patient. The treatment approach proposed here may become an option in cases in which there is no esthetic impairment or need for preservation of alveolar ridge anatomy.

One factor contributing to the success or failure of dental implants is their diameter. A greater diameter results in an increase of surface area, corresponding to additional primary stability of the implant [29]. However, this compensation is often not possible and the diameter has to be reduced because of the loss of alveolar ridge width. Therefore, the present study also evaluated radiographically the bone loss around regular diameter $(3.75 \mathrm{~mm})$ implants in order to help choose the diameter of dental implants, which is directly related to available bone volume, permitting implant placement in sites with low bone availability without the need for bone grafting. Other features such as space between neighboring teeth, esthetic requirements, occlusal load, and type of occlusion have been investigated.

Study limitations include: first, a clinical research was carried out involving a small number of patients. This study consisted of forty short implants total ( $n=20 /$ group). Second, the times set for analysis in this study were 7, 30 and 90 days after surgery. Future studies investigating the influence of different type of implants, type of bone and different sites of implant placement are required to include a larger sample size and a longer time for analysis. Thus, extrapolating the present findings to other situations is not recommended.

\section{Conclusions}

Within the limitations of this study, we conclude that $6-\mathrm{mm}$ long morse taper connection implants present levels of crestal bone remodeling similar to those of $8-\mathrm{mm}$ long implants which have been installed in reportedly healthy adults with adequate oral hygiene and sufficient alveolar bone volume and type I-III bone quality at the implant recipient site.

\section{Conflict of Interest}

The authors report no conflicts of interest related to this study.

\section{References}

1. Hermann JS, Buser D, Schenk RK, Cochran DL (2000) Crestal bone changes around titanium implants. A histometric evaluation of unloaded non-submerged and submerged implants in the canine mandible. J Periodontol 71: 1412-1424.

2. Oh TJ, Yoon J, Misch CE, Wang HL (2002) The causes of early implant bone loss: myth or science? J Periodontol 73: 322-333.

3. Albrektsson T, Zarb G, Worthington P, Eriksson AR (1986) The longterm efficacy of currently used dental implants: a review and proposed criteria of success. Int J Oral Maxillofac Implants 1: 11-25.

4. Novaes $A B \mathrm{Jr}$, de Oliveira RR, Muglia VA, Papalexiou V, Taba M (2006) The effects of interimplant distances on papilla formation and crestal resorption in implants with a morse cone connection and a platform switch: a histomorphometric study in dogs. J Periodontol 77: 1839-1849.

5. Novaes AB Jr, Barros RR, Muglia VA, Borges GJ (2009) Influence of interimplant distances and placement depth on papilla formation and crestal resorption: a clinical and radiographic study in dogs. J Oral Implantol 35: 18-27.

6. Barros RR, Novaes AB Jr, Muglia VA, lezzi G, Piattelli A (2010) Influence of interimplant distances and placement depth on periimplant bone remodeling of adjacent and immediately loaded Morse cone connection implants: A histomorphometric study in dogs. Clin Oral Implants Res 21: 371-378.

7. Smith DE, Zarb GA (1989) Criteria for success of osseointegrated endosseous implants. J Prosthet Dent 62: 567-572.

8. Coelho PG, Suzuki M, Guimaraes MV, Marin C, Granato R, et al. (2010) Early bone healing around different implant bulk designs and surgical techniques: A study in dogs. Clin Implant Dent Relat Res 12: 202-208.

9. Donovan R, Fetner A, Koutouzis T, Lundgren T (2010) Crestal bone changes around implants with reduced abutment diameter placed non-submerged and at subcrestal positions: A 1-year radiographic evaluation. J Periodont 81: 428-434.

10. Karoussis IK, Brägger U, Salvi GE, Bürgin W, Lang NP (2004) Effect of implant design on survival and success rates of titanium oral implants: a 10-year prospective cohort study of the ITI Dental Implant System. Clin Oral Implants Res 15: 8-17.

11. Muftu A, Chapman RJ (1998) Replacing posterior teeth with freestanding implants: four-year prosthodontic results of a prospective study. J Am Dent Assoc 129: 1097-1102.

12. Merz BR, Hunenbart S, Belser UC (2000) Mechanics of the implant-abutment connection: an 8-degree taper compared to a butt joint connection. Int J Oral Maxillofac Implants 15: 519-526.

13. das Neves FD, Fones D, Bernardes SR, do Prado CJ, Neto AJ (2006) Short implants--an analysis of longitudinal studies. Int J Oral Maxillofac Implants 21: 86-93.

14. Mangano C, Mangano F, Piattelli A, lezzi G, Mangano A, et al. (2009) Prospective clinical evaluation of 1920 Morse taper connection implants: Results after 4 years of functional loading. Clin Oral Implants Res 20: 254-261. 
15. Mangano $C$, Mangano F, Shibli JA, Tettamanti L, Figliuzzi M, et al. (2011) Prospective evaluation of 2,549 Morse taper connection implants: 1- to 6-year data. J Periodontol 82: 52-61.

16. Renouard F, Nisand D (2006) Impact of implant length and diameter on survival rates. Clin Oral Implants Res 17 Suppl 2: 35-51.

17. Vela-Nebot X, Rodriguez-Ciurana X, Rodado-Alonso C, Segala, Torres M (2006) Benefits of an implant platform modification technique to reduce crestal bone resorption. Implant Dent 15: 313-320.

18. Jemt T, Lekholm $U$ (1995) Implant treatment in edentulous maxillae: a 5-year follow-up report on patients with different degrees of jaw resorption. Int J Oral Maxillofac Implants 10: 303-311.

19. Winkler S, Morris HF, Ochi S (2000) Implant survival to 36 months as related to length and diameter. Ann Periodontol 5: 22-31.

20. Naert I, Koutsikakis G, Duyck J (2002) Biologic outcome of implantsupported restorations in the treatment of partial edentulism. Part I: A longitudinal clinical evaluation. Clin Oral Implants Res 13: 381-389.

21. Higuchi KW, Folmer T, Kultje C (1995) Implant survival rates in partially edentulous patients: a 3-year prospective multicenter study. J Oral Maxillofac Surg 53: 264-268.

22. Misch CE (2005) Short dental implants: a literature review and rationale for use. Dent Today 24: 64-66, 68.

23. Misch CE, Steignga J, Barboza E, Misch-Dietsh F, Cianciola LJ, et al. (2006) Short dental implants in posterior partial edentulism: a multicenter retrospective 6-year case series study. J Periodontol 77: 1340-1347.

24. Minsk L, Polson AM, Weisgold A, Rose LF, Sanavi F, et al. (1996) Outcome failures of endosseous implants from a clinical training center. Compend Contin Educ Dent 17: 848-850, 852-854, 856 passim.

25. Tawil G, Younan R (2003) Clinical evaluation of short, machinedsurface implants followed for 12 to 92 months. Int J Oral Maxillofac Implants 18: 894-901.
26. Weber HP, Buser D, Donath K, Fiorellini JP, Doppalapudi V, et al. (1996) Comparison of healed tissues adjacent to submerged and non-submerged unloaded titanium dental implants. A histometric study in beagle dogs. Clin Oral Implants Res 7: 11-19.

27. Misch CE, Perel ML, Wang HL, Sammartino G, Galindo-Moreno P, et al. (2008) Implant success, survival, and failure: The International Congress of Oral Implantologists (ICOI) Pisa consensus conference. Implant Dent. 17: 5-15.

28. Grant BT, Pancko FX, Kraut RA (2009) Outcomes of placing short dental implants in the posterior mandible: a retrospective study of 124 cases. J Oral Maxillofac Surg 67: 713-717.

29. Bozkaya D, Muftu S, Muftu A (2004) Evaluation of load transfer characteristics of five different implants in compact bone at different load levels by finite elements analysis. J Prosthet Dent 92: 523-30.

30. Misch CE, Dietsh-Misch F, Hoar J, Beck G, Hazen R, et al. (1999) A bone quality-based implant system: first year of prosthetic loading. J Oral Implantol 25: 185-197.

31. Misch CE, Bidez MW, Sharawy M (2001) A bioengineered implant for a predeter-mined bone cellular response to loading forces. A literature review and case report. J Periodontol 72: 1276-86.

32. Degidi M, Perrotti V, Shibli JA, Novaes AB, Piattelli A, et al. (2011) Equicrestal and subcrestal dental implants: a histologic and histomorphometric evaluation of nine retrieved human implants. J Periodontol 82: 708-715.

33. Orsini G, Fanali S, Scarano A, Petrone G, di Silvestro S, et al. (2000) Tissue reactions, fluids, and bacterial infiltration in implants retrieved at autopsy: a case report. Int J Oral Maxillofac Implants 15: $283-286$

34. Piattelli A, Vrespa G, Petrone G, lezzi G, Annibali S, et al. (2003) Role of the microgap between implant and abutment: $A$ retrospective histologic evaluation in monkeys. J Periodontol 74: 346-352.

35. Prosper L, Redaelli S, Pasi M, Zarone F, Radaelli G, et al. (2009) A randomized prospective multicenter trial evaluating the platformswitching technique for the prevention of postrestorative crestal bone loss. Int J Oral Maxillofac Implants 24: 299-308. 